\title{
INSERÇÃO EM CADEIAS GLOBAIS DE VALOR: INFLUÊNCIA DA GOVERNANÇA EXTERNA SOBRE A INDÚSTRIA DO MOBILIÁRIO DO ESTADO DE SANTA CATARINA*
}

\author{
Fabiano Geremia' \\ Renato Ramos Campos
}

\begin{abstract}
Resumo
Este estudo analisa as relações das empresas do mobiliário de Santa Catarina que estão inseridas em arranjos produtivos locais com os compradores internacionais. O foco específico de análise é a identificação das possibilidades de upgrading tecnológico através da aprendizagem interativa com os compradores internacionais. A indústria do mobiliário de Santa Catarina é responsável por $50 \%$ das exportações nacionais de móveis e, nos principais mercados consumidores, EUA e Europa, a comercialização é realizada através de grandes distribuidores internacionais. Pretende-se investigar a possibilidade das empresas, em aglomerados produtivos, obterem vantagens competitivas sustentáveis nos mercados internacionais, parcialmente associadas às suas relações no âmbito das cadeias globais. Avalia-se, especificamente, os processos de aprendizagem tecnológica associados às relações que as empresas do mobiliário em Santa Catarina estabelecem com as cadeias globais. Com base no referencial Neo-Schumpeteriano, que aborda os processos de aprendizagem tecnológica, foi realizada pesquisa de campo usando questionário estruturado para a análise das características das capacitações tecnológicas das empresas catarinenses selecionadas, localizadas em aglomerações produtivas de Santa Catarina.
\end{abstract}

' Doutorando em economia pela Universidade Federal do Rio de Janeiro e bolsista da Coordenação de Aperfeiçoamento de pessoal de Nível Superior - Capes. e-mail: fabianogeremia@ie.ufri.br

2 Prof. Departamento de Economia da Universidade Federal de Santa Catarina. e-mail: recampos@cse.ufsc.br

* Artigo recebido em julho de 2007 e aceito para publicação em março de 2008. 
Palavras-chave: indústria de móveis; aprendizagem tecnológica; cadeias globais.

Classificação JEL: L15

\section{INTRODUÇÃO}

O processo inovativo está associado a capacidade das empresas de estabelecer relações interativas com os mais diversos agentes econômicos. Com isso, os avanços das tecnologias de informação e comunicação desempenham um papel preponderante ao permitirem uma fragmentação das diversas etapas do processo produtivo. Através deste sistema a produção pode ser feita em diversas unidades produtivas ou até em diversas partes do globo e reintegradas novamente, constituindo assim redes de subcontratação nacionais e internacionais. A integração produtiva realizada entre agentes globais instituem as chamadas Cadeias Globais de Valor (CGV) ou Produção em Redes Globais (PRG). A produção em CGV e PRG busca beneficiar-se especialmente de diferentes estruturas de custos, motivadas por diferentes condições de fabricação. A corrente teórica que analisa esta forma de fabricação, defende que a inserção em CGV e PRG pode proporcionar efeitos de longo alcance, notadamente pela possibilidade de difusão de conhecimentos, de habilidades, de idéias, de aprendizagem e upgrading tecnológicos capturados através de externalidades coletivas intensificando assim o processo inovativo e fortalecendo as condições competitivas. Desta forma, o estudo pretende analisar o alcance proporcionado pela inserção em CGV e PRG aos arranjos produtivos do mobiliário selecionados.

$\mathrm{O}$ artigo tem a seguinte estrutura: apresentação das principais referências para a análise, destacando-se os padrões de aprendizagem na indústria de móveis e os tipos de upgrading sugeridos na literatura recente; levantamento dos principais fatores do padrão de concorrência, com base no trabalho de KAPLINSKY, et al (2003), segundo os tipos de compradores existentes no mercado internacional de móveis; identificação das diferentes relações entre os compradores externos e os fornecedores nacionais e seus efeitos sobre as possibilidades de upgrading dos fornecedores nacionais; apresentação das 
Inserção em cadeias globais de valor: influência da governança externa sobre a indústria do mobiliário do Estado de Santa Catarina

principais características da indústria do mobiliário em Santa Catarina e os arranjos produtivos locais que serão objetos desta análise e; como conclusão, apresentação das especificidades de inserção no comércio internacional e as possibilidades de upgrading.

\section{PROCESSOS DE APRENDIZAGEM TECNOLÓGICA E AS POSSIBILIDADES DE UPGRADING: AS REFERÊNCIAS PARA A ANÁLISE}

O regime tecnológico ${ }^{3}$ e as estruturas de mercado que condicionam os padrões de aprendizagem na indústria do mobiliário apresentam as seguintes características: a) as inovações se originam na indústria produtora de equipamentos e insumos; b) as oportunidades tecnológicas possibilitam principalmente inovações e melhoramentos nos processos e em design do produto; c) a transferência tecnológica ocorre incorporada nos equipamentos cuja produção é principalmente internacional e; d) são baixas tanto as barreiras à entrada, quanto às possibilidades de apropriação do resultado econômico da introdução de inovações. (Rabelotti, et al, 2003).

Neste sentido, os padrões de aprendizagem ${ }^{4}$ se fundamentam nas condições locais de absorção de inovações e melhoramentos, ou seja, nas possibilidades das interações locais estimularem, internamente, as trocas de conhecimentos tácitos e capacitação para seleção e incorporação de novas tecnologias, buscando ganhos, principalmente nos melhoramentos de processos. Também as modificações no design são centrais para os processos competitivos. A construção de capacitações exige, além de interações locais que podem ser proporcionadas por sua participação em arranjos ou sistemas produtivos locais ${ }^{5}$, fortes interações com agentes de fora destas aglomerações. A inserção destes sistemas locais em cadeias globais de valor ${ }^{6}$ torna-se uma dimensão importante da avaliação das capacidades competitivas do ambiente local.

${ }^{3}$ Sobre regime tecnológico ver Breschi e Malerba (1997).

${ }^{4}$ Sobre os processos de aprendizagem ver Lundwal (1992), Malerba (1992), Schmitz e Knorringa (1999) e Campos et al, (2003).

${ }^{5}$ Sobre arranjos e sistemas produtivos locais ver Cassiolato et al. (2003).

${ }^{6}$ A literatura identifica dois tipos de "cadeias globais de valor": cadeias coordenadas por produtores e cadeias coordenadas por compradores (Humphrey e Schmitz, 200 I). Para esta análise importa apenas o segundo tipo. 
Rabellotti et al, (2003, p. 05), identifica três tipos de upgrading tecnológico:

(a) process upgrading, transforming inputs into outputs more efficiently by re-organizing the production system or introducing superior technology; b) Product upgrading, is moving into more sophisticated product lines in terms of increased unit values; c) functional upgrading, is acquiring new, superior functions in the chain, such as design or marketing or abandoning existing low-value added functions to focus on higher value added activities.

As evidências empíricas sobre os impactos da inserção de sistemas produtivos locais em cadeias globais de valor, considerando os padrões de aprendizagem em setores tradicionais como acima descrito, sugerem que os upgrading em processo podem ser estimulados pelas interações com os agentes pertencentes às cadeias globais de valor. No entanto, o upgrading de produto e o funcional que indica a possibilidade de moverse para segmentos com maior agregação de valor nas cadeias produtivas, tende a ser mais reduzido.

Este trabalho abrange a análise de dois arranjos produtivos da indústria do mobiliário em Santa Catarina, sendo um na região Oeste do Estado, de formação bastante recente, e outro na região Norte, já consolidado como o principal pólo exportador de móveis do Brasil. As informações referente ao arranjo produtivo da região Oeste de Santa Catarina foram obtidas através de entrevistas realizadas com 67 empresas, em agosto de 2003, com participação de (40) quarenta micro, (24) vinte quatro pequenas e (03) médias empresas, bem como a Associação do mobiliário local. Enquanto que as informações para o estudo do arranjo do mobiliário da microrregião de São Bento do Sul, região Norte do Estado, foram obtidas através de entrevistas realizadas em abril de 2004, com participação de (03) três pequenas, (02) duas médias e (02) duas grandes empresas, além de entrevistas com (02) agentes de exportação e a Abimóvel ${ }^{7}$.

${ }^{7}$ Abimóvel - Associação Brasileira da Indústria do Mobiliário. 
Inserção em cadeias globais de valor: influência da governança externa sobre a indústria do mobiliário do Estado de Santa Catarina

No entanto, no decorrer da pesquisa percebeu-se que por ser de desenvolvimento recente, o Arranjo Produtivo da região Oeste de Santa Catarina é menos denso, em termos de integração, com o mercado externo e com foco predominantemente no mercado doméstico. Desta forma, a análise dos efeitos da inserção internacional através CGV e PRG concentra-se predominantemente no arranjo produtivo do mobiliário da região norte de Santa Catarina.

Com base nestas informações identificaram-se as relações das empresas dos arranjos locais com seus principais compradores externos. Nas entrevistas procurou-se identificar: a) as formas de cooperação realizadas; b) as possibilidades de transferência de informações entre os agentes; c) as dificuldades de inserção no mercado externo e; d) as principais vantagens derivadas das formas de inserção. Com base nestas informações procurou-se avaliar as características e as possibilidades do tipo de upgrading proporcionado por relações interativas com os compradores internacionais.

\section{FATORES DE COMPETITIVIDADE NO MERCADO INTER- NACIONAL DE MÓVEIS E FORMAS DE RELAÇÃO COM OS COMPRADORES}

As características da demanda, segundo os diferentes tipos de agentes compradores no mercado internacional, estão relacionados na figura 1. Kaplinsky identifica três tipos de compradores: a) redes de lojas varejistas, (Multi-store retailer), compram de um grande número de fornecedores localizados em um grande número de países e possuem uma rede de lojas localizadas em diversos países; b) compradores varejistas em menor escala, (one-shop retailer), compram de um número menor de fornecedores localizados em um número menor de países e;c) compradores especializados, (specialized buyer), possuem diversos fornecedores em diversos países e vendem em apenas um país ou região. Estes últimos podem ter escalas de compra diferenciadas. (KAPLINSKY, 2003, p. 10). 


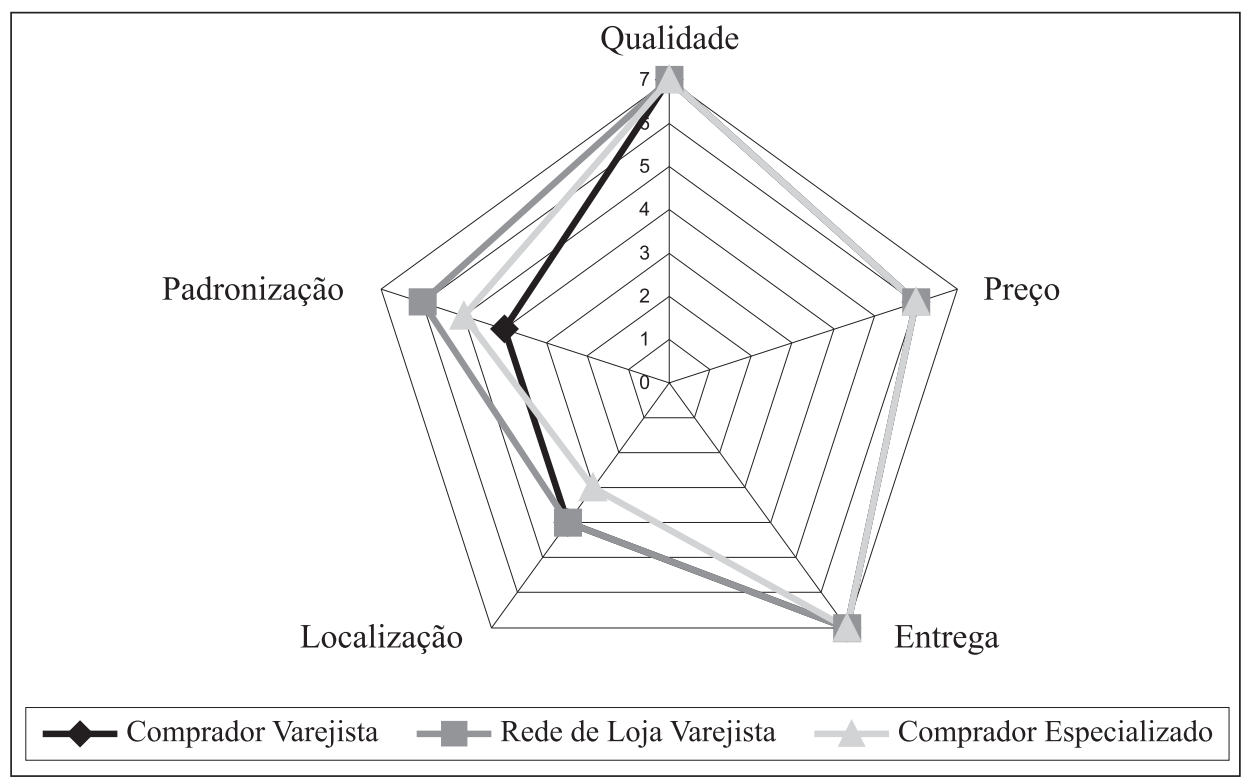

Fonte: Kaplinsky et al. (2003).

Figura 1 - Característica da Demanda Segundo os Diferentes Tipos de Agentes Compradores de Mobília no Mercado Internacional

Cada comprador prioriza distintos requisitos de competitividade. Conforme se percebe, para as redes de lojas varejistas, a localização do fornecedor e a padronização de serviços, de rotina e do produto são fatores relevantes que os diferenciam dos demais tipos de compradores. Conforme esclarece Kaplinsky, de forma geral, os fornecedores enfrentam menores exigências quando fornecem para compradores varejistas em menor escala e compradores especializados do que para as redes de lojas varejistas que atuam no âmbito mundial.

Segundo os diferentes tipos de compradores, as características da demanda têm exigido da indústria do mobiliário o desenvolvimento de novas capacitações, notadamente a partir da década de noventa. Destacam-se, a necessidade de aprimoramentos em design, desenvolvimento de logística e, principalmente, a capacidade para desenvolver novas atividades na cadeia. Neste contexto, a integração entre fornecedores e compradores tornou-se extremamente importante na obtenção de informações em processos de aprendizagem interativa. Kaplinsky et al. (2003, p. 11). 
Inserção em cadeias globais de valor: influência da governança externa sobre a indústria do mobiliário do Estado de Santa Catarina

Kaplinsky analisa, segundo a visão dos compradores externos, como as relações entre compradores externos e fornecedores locais afetam as possibilidades de upgrading por diferentes tipos de compradores. O quadro 1 sintetiza esta análise. Não é provável a ocorrência de upgrading em produto nas relações com "compradores varejistas" e é bastante reduzida tanto nas relações com as "redes de lojas varejistas" quanto nas relações com "compradores especializados".

De forma geral observa-se que, do ponto de vista do fornecedor nacional, as possibilidades de aprendizagem interativa podem lhe proporcionar, principalmente, o upgrading em processo devido às maiores freqüências nas ações interativas com os compradores.

No que se refere ao tipo de relações interativas, as que ocorrem com um maior grau de freqüência são as que se estabelecem no âmbito dos processos produtivos, interações no processo produtivo, e as referentes às trocas de informações sobre tendências de mercado. A freqüência das ações de natureza cooperativa é muito reduzida.

\begin{tabular}{|l|c|c|c|c|c|c|}
\hline \multirow{2}{*}{ Relações Interativas } & \multicolumn{2}{|c|}{$\begin{array}{c}\text { Comprador } \\
\text { varejista }\end{array}$} & \multicolumn{2}{c|}{$\begin{array}{c}\text { Rede de } \\
\text { loja varejista }\end{array}$} & \multicolumn{2}{c|}{$\begin{array}{c}\text { Comprador } \\
\text { especializado }\end{array}$} \\
\cline { 2 - 7 } & Freqüencia & \multicolumn{2}{|c|}{ Freqüência } & \multicolumn{2}{c|}{ Freqüência } \\
\cline { 2 - 7 } & Produto & Processo & Produto & Processo & Produto & Processo \\
\hline $\begin{array}{l}\text { Interações no processo } \\
\text { produtivo }\end{array}$ & $\begin{array}{c}\text { Rara- } \\
\text { mente }\end{array}$ & $\begin{array}{c}\text { Algumas } \\
\text { vezes }\end{array}$ & Nunca & $\begin{array}{c}\text { Algumas } \\
\text { vezes }\end{array}$ & $\begin{array}{c}\text { Algumas } \\
\text { vezes }\end{array}$ & Sempre \\
\hline $\begin{array}{l}\text { Informações sobre } \\
\text { tendências de mercado } \\
\text { (em produtos e } \\
\text { processos) }\end{array}$ & $\begin{array}{c}\text { Rara- } \\
\text { mente }\end{array}$ & $\begin{array}{c}\text { Rara- } \\
\text { mente }\end{array}$ & $\begin{array}{c}\text { Rara- } \\
\text { mente }\end{array}$ & $\begin{array}{c}\text { Algumas } \\
\text { vezes }\end{array}$ & $\begin{array}{c}\text { Rara- } \\
\text { mente }\end{array}$ & $\begin{array}{c}\text { Algumas } \\
\text { vezes }\end{array}$ \\
\hline $\begin{array}{l}\text { Ações cooperativas } \\
\text { Rara- } \\
\text { mente }\end{array}$ & $\begin{array}{c}\text { Rara- } \\
\text { mente }\end{array}$ & $\begin{array}{c}\text { Algumas } \\
\text { vezes }\end{array}$ & $\begin{array}{c}\text { Rara- } \\
\text { mente }\end{array}$ & $\begin{array}{c}\text { Rara- } \\
\text { mente }\end{array}$ & $\begin{array}{c}\text { Rara- } \\
\text { mente }\end{array}$ \\
\hline treinamento & $\begin{array}{c}\text { Rara- } \\
\text { mente }\end{array}$ & Nunca & $\begin{array}{c}\text { Rara- } \\
\text { mente }\end{array}$ & $\begin{array}{c}\text { Rara- } \\
\text { mente }\end{array}$ & Nunca & $\begin{array}{c}\text { Rara- } \\
\text { mente }\end{array}$ \\
\hline $\begin{array}{l}\text { Proporcionar auxílio } \\
\text { financeiro }\end{array}$ & $\begin{array}{c}\text { Rara- } \\
\text { mente }\end{array}$ & Nunca & $\begin{array}{c}\text { Rara- } \\
\text { mente }\end{array}$ & $\begin{array}{c}\text { Rara- } \\
\text { mente }\end{array}$ & $\begin{array}{c}\text { Rara- } \\
\text { mente }\end{array}$ & $\begin{array}{c}\text { Rara- } \\
\text { mente }\end{array}$ \\
\hline
\end{tabular}

Fonte: Elaborado a partir de Kaplinsky et al, (2003, p. 13)

Quadro 1 - Percepção dos Compradores Externos de Mobília como Geradores de Upgrading para as Empresas fornecedoras 
A atividade de design é realizada de forma distinta pelos diferentes compradores. Os "compradores varejistas" não desenvolvem seu próprio design. As "redes de lojas varejistas" e os "compradores especializados", ou adquirem seus design de escritórios especializados ou investem significativos recursos em pesquisa e em desenvolvimento de design próprio. De forma geral, os compradores especializados procuram assegurar o domínio das atividades de design, pois o consideram como uma importante fonte de vantagem competitiva no comércio mundial.

\section{AS CARACTERÍSTICAS DA INDÚSTRIA DO MOBILIÁRIO EM SANTA CATARINA}

A indústria do mobiliário no Estado de Santa Catarina possui um relevante papel na geração de emprego e renda, representando em torno de 25.700 empregos diretos ${ }^{8}$, além de apresentar significativo desempenho no comércio exterior com expressivos saldos comerciais. Conforme indica a tabela 1, existem 1.818 empresas no Estado com ampla predominância de micro e pequenas empresas 9 .

Tabela 1 - Quantidade de Empresas da Indústria do Mobiliário no Estado de Santa Catarina - Segundo o Segmento Produtivo e Tamanho das Empresas -2001 .

\begin{tabular}{|c|c|c|c|c|c|}
\hline Classificação & Micro & Pequena & Média & Grande & Total \\
\hline $\begin{array}{l}\text { Fabricação de móveis com } \\
\text { predominância de madeira }\end{array}$ & 1429 & 191 & 47 & 2 & 1669 \\
\hline $\begin{array}{l}\text { Fabricação de móveis com } \\
\text { predominância de metal }\end{array}$ & 56 & 11 & - & - & 67 \\
\hline $\begin{array}{l}\text { Fabricação de móveis de } \\
\text { outros materiais }\end{array}$ & 74 & 7 & 1 & - & 82 \\
\hline Total & 1559 & 209 & 48 & 2 & 1818 \\
\hline
\end{tabular}

Fonte: RAIS/MTE - 2001

9 Entende-se como micro as empresas que possuem até 19 funcionários, pequenas as que possuem entre 20 e 99 funcionários, médias as que possuem entre 100 e 499 e grandes as que possuem acima de 500 funcionários. 
Inserção em cadeias globais de valor: influência da governança externa sobre a indústria do mobiliário do Estado de Santa Catarina

A microrregião de São Bento do Sul destaca-se na fabricação de móveis e esta atividade industrial já apresenta também um alto quociente locacional em microrregiões como São Miguel do Oeste e Chapecó, no Oeste do Estado de Santa Catarina. A tendência de aumento das especializações em outras regiões do Estado se reflete numa relativa desconcentração espacial da atividade, mas permanece a concentração nos espaços de formação inicial.

O desenvolvimento da indústria do mobiliário no Estado está diretamente ligado ao processo de colonização. As regiões onde se encontram os principais arranjos produtivos do mobiliário foram colonizadas por imigrantes alemães e italianos que trouxeram consigo suas culturas e, sobretudo, as técnicas da indústria manufatureira.

Os aumentos das exportações catarinenses de móveis coincidem com os graves problemas enfrentados pela economia brasileira a partir dos anos 80 , forçando as empresas a buscarem alternativas frente às restrições de demanda interna. Muitas empresas, apesar do seu bom nível técnico, encontravam-se com graves restrições financeiras e com pouca ou nenhuma experiência no mercado externo.

Nos anos 80 surgiram inúmeros agentes de exportação de móveis nos principais arranjos produtivos, principalmente na região Norte, que possibilitaram a intermediação entre os compradores internacionais e as empresas do mobiliário nacional, funcionando como uma alternativa aos custos de manter um departamento de vendas no exterior e ampliando a divisão de trabalho no âmbito dos arranjos produtivos. Estes exportadores, inicialmente, agiam como elo de ligação com os compradores internacionais que, por sua vez, eram agentes importadores.

Entretanto, o que parecia ser uma alternativa para a inserção no mercado internacional acabou desenvolvendo uma estrutura sólida e ampla. Em decorrência tanto de seu porte quanto das restrições macroeconômicas, especificamente no início do "Plano Real”, quando o Real esteve sobrevalorizado, as empresas não realizavam exportações regulares e evitavam internalizar as atividades especializadas em comércio exterior, abrindo espaço para a consolidação dos agentes exportadores locais e, principalmente, consolidaram como principal forma de acesso aos mercados internacionais suas 
relações com os compradores atacadistas ou outros agentes importadores. A pesquisa identificou 36 agentes exportadores localizados na região Norte do Estado, que trabalham exclusivamente com a exportação de móveis. Estes agentes também são contratados pelas empresas do arranjo do mobiliário da região Oeste de Santa Catarina.

A seguir, apresenta-se, os principais resultados da pesquisa com as empresas localizadas no arranjo produtivo moveleiro da região Oeste e da microrregião de São Bento do Sul, no Norte de Santa Catarina. No primeiro caso estudado, a formação do aglomerado é bastante recente, tendo-se desenvolvido principalmente nos anos 90. No segundo caso, o arranjo produtivo formou-se desde os anos 60 , consolidando-se como importante pólo exportador da indústria moveleira nacional.

\subsection{Arranjo produtivo moveleiro da região oeste de Santa Catarina}

A região em estudo ${ }^{10}$ é constituída por 59 cidades, dentre as quais 37 possuem empresas moveleiras ${ }^{11}$. Cerca de $70 \%$ das empresas da região Oeste e $75,3 \%$ do emprego deste segmento industrial estão concentrados nos municípios de Chapecó, Coronel Freitas, Nova Erechim, Pinhalzinho, Modelo, São Lourenço do Oeste, São Miguel D'Oeste, São José do Cedro e Maravilha. Apesar de não constituírem uma área geográfica contígua, de acordo com o IBGE, todos estão localizados em duas microrregiões homogêneas limítrofes. Além disto, a similaridade das características da indústria, principalmente pela presença de micro e pequenas empresas em todos os municípios e a dimensão institucional que caracteriza um espaço comum, permitem considerar este conjunto como um arranjo produtivo localizado da indústria do mobiliário, cujo núcleo principal é formado pelos municípios acima referidos.

${ }^{10}$ Os municípios da região Oeste de Santa Catarina, definidos para o estudo, compreendem a microrregião de São Miguel D' Oeste e a microrregião de Chapecó.

"' Os municípios que compreendem a região em estudo e que possuem fábricas de móveis são: Águas de Chapecó, Águas Frias, Bom Jesus D' Oeste, Caibi, Campo Erê, Chapecó, Coronel Freitas, Cunha Porã, Formosa do Sul, Irati, Maravilha, Modelo, Nova Erechim, Palmitos, Pinhalzinho, Quilombo, São Carlos, São Lourenç̧o do Oeste, Saudades, Serra Alta, Sul Brasil e União D' Oeste, Anchieta, Descanso, Dionísio Cerqueira, Guaraciaba, Guaraja do Sul, Iporã do Oeste, Itapiranga, Mondaí, Palma Sola, Princesa, Riqueza, São João do Oeste, São José do Cedro, São Miguel do Oeste e Tunápolis. (RAIS/MTE-200I). 
Inserção em cadeias globais de valor: influência da governança externa sobre a indústria do mobiliário do Estado de Santa Catarina

Existem 293 empresas da indústria do mobiliário neste arranjo produtivo, com presença aproximada de $99 \%$ de micro e pequenas empresas, sendo que as demais são médias e inexistem grandes empresas no local. As que produzem móveis com predominância de madeira representam $89,5 \%$ das empresas do arranjo, 4,4\% com predominância de metal e 5,96\% que produzem móveis com predominância de outros materiais. O principal produto do arranjo local é móvel residencial, com pequena participação de móvel para escritório. Estas empresas geram 3.823 empregos diretos, representando cerca de $5 \%$ dos empregos da economia na região. O número médio de empregos por empresa no arranjo é de 13 trabalhadores. Deste total, cerca de $29,1 \%$ são criados pelas micro, $55,9 \%$ pelas pequenas e $15 \%$ pelas médias empresas. (RAIS/MTE,2001).

As empresas do arranjo produtivo do mobiliário da região Oeste de Santa Catarina exportam aproximadamente 10\% da produção. Diversas empresas, particularmente as médias, estão integradas com os compradores externos. No entanto, há também algumas pequenas empresas que comercializam no mercado externo. A maior parte destas exporta para mercados da América Latina e Oriente Médio e poucas comercializam no mercado europeu e estadunidense.

Através de agentes exportadores, as empresas do arranjo vendem principalmente para os "compradores especializados" que fornecem o protótipo e o design do móvel a ser produzido. De acordo com as empresas, o principal fator crítico explorado pelos compradores é o preço. A característica deste tipo de comprador é a posse de grandes carteiras de fornecedores em diversos países, sugerindo uma intensa concorrência em preço no mercado mundial.

Através da interação com os "compradores especializados", as médias empresas, especialmente, estão logrando a realização de upgrading em processo. Entretanto, as possibilidades desta realização são bastante restritas devido às fracas relações cooperativas com este tipo de comprador internacional. Um importante fator que dificulta este tipo de upgrading é de origem interna ao arranjo. A reduzida divisão do trabalho no interior do arranjo dificulta as complementaridades locais e, por conseqüência, a flexibilidade na produção. 


\subsection{Arranjo produtivo moveleiro da região norte de Santa Catarina}

O arranjo produtivo da região Norte é formado por 03 municípios ${ }^{12}$ localizados na microrregião de São Bento do Sul. São 294 empresas da indústria do mobiliário e cerca de $90 \%$ são micro e pequenas, 27 são médias e 02 são grandes empresas. As que produzem móveis com predominância de madeira representam $98,6 \%$ das empresas do arranjo. O principal produto do arranjo local é móvel residencial de pínus, com pequena participação de móvel de madeira de lei. Estas empresas geram 9.803 empregos diretos, representando aproximadamente $30 \%$ dos empregos da economia na região. No arranjo moveleiro, o número médio é de 33 trabalhadores por empresa, cerca de 13,6\% da força de trabalho formal está nas micro, 25,2\% nas pequenas, 45,6\% nas médias e 15,6\% nas grandes empresas. (RAIS/MTE,2001).

Este arranjo produtivo teve sua origem por volta de 1960 e somente a partir dos anos 70 passou a exportar. Nos anos 80 , o processo de inserção externa intensificou-se e cerca de $80 \%$ da sua produção passou a ser exportada, tornando o Estado de Santa Catarina o principal exportador de mobília do Brasil ${ }^{13}$.

Neste arranjo, os principais compradores são os "compradores especializados". Contudo, em proporções menores, a produção é comercializada também com "compradores varejistas" e "redes de lojas varejistas". Com exceção de "uma" grande empresa, a comercialização para os principais mercados mundiais, EUA e EUROPA, ocorre estritamente através da intermediação de agentes exportadores nacionais e internacionais.

A figura 2 identifica as principais formas de interação entre as empresas e os compradores entre os anos de 2001 a 2003, mais especificamente com os "compradores especializados". O design é desenvolvido exclusivamente pelos compradores e repassados às empresas. Desta forma, há a necessidade da capacitação do fornecedor para adaptar e melhorar os processos. As empresas consideram que o acesso a novos design pode ampliar suas capacitações tanto no processo quanto no desenvolvimento de novos produtos. Tais capacitações poderiam lhes proporcionar acesso aos "compradores varejistas" e, possivelmente, também às "redes de lojas varejistas" mais

${ }^{12}$ Os municípios que compreendem a região em estudo são: Rio Negrinho, São Bento do Sul e Campo Alegre. (RAIS/MTE-200I).

${ }^{13} \mathrm{O}$ estado de Santa Catarina foi responsável por 49,6\% das exportações brasileiras da indústria do mobiliário no ano de 2003. Percentuais semelhantes também são evidenciados nos anos anteriores. (MDIC/AliceWeb, 2004) 
Inserção em cadeias globais de valor: influência da governança externa sobre a indústria do mobiliário do Estado de Santa Catarina

exigentes. No entanto, o que se observa é que as relações com os atuais compradores externos, "compradores especializados" e agentes exportadores, são predominantemente de natureza comercial, sem incluir outras atividades de natureza mais cooperativa.

A capacitação de recursos humanos inexiste como forma de cooperação entre os compradores externos e as empresas, mas em função das necessidades e exigências impostas pelos compradores, as empresas buscam constantemente realizar treinamento e capacitações de recursos humanos. Da mesma forma, não existe cooperação entre as empresas e os compradores no que se refere ao auxílio financeiro. Em algumas ocasiões, dependendo das condições acordadas no contrato de venda, pode ocorrer o pagamento antecipado, o que pode reduzir problemas como por exemplo, a inadimplência. A participação em feiras internacionais é considerada pelas empresas como um importante elemento para a promoção comercial, mesmo de forma limitada, pois nas principais feiras do mobiliário mundial, os compradores atacadistas não utilizam a marca das empresas fornecedoras.

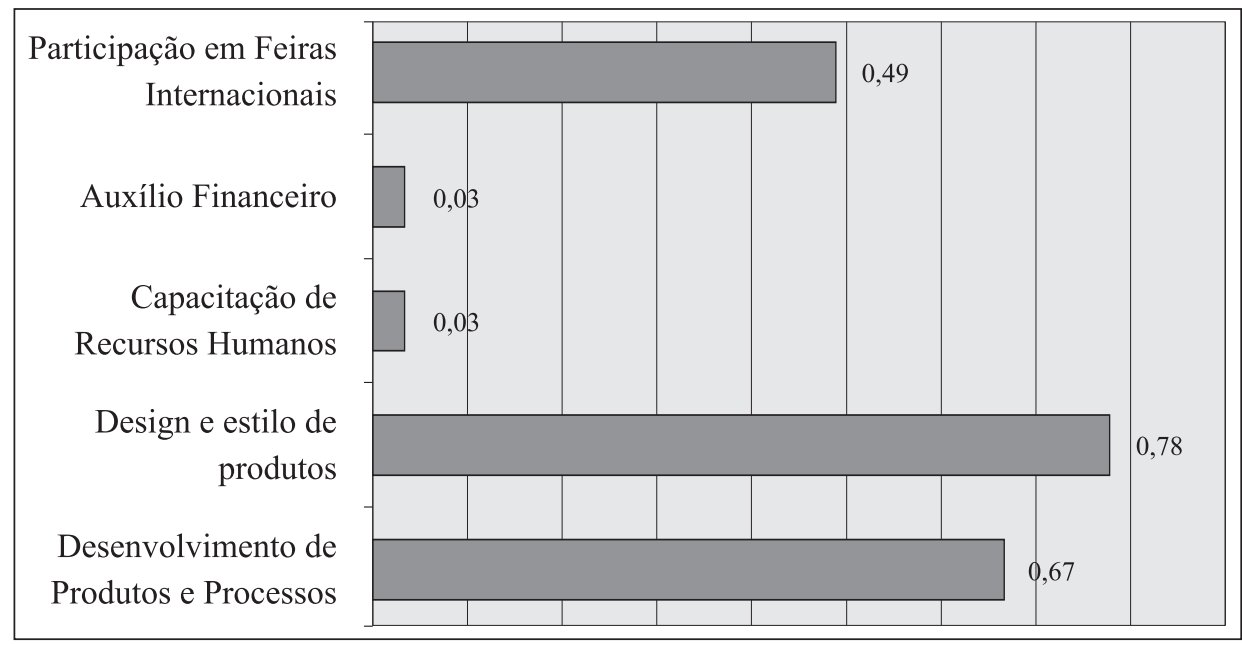

Fonte: Pesquisa de Campo

$*$ Índice $=\left(0^{*} \mathrm{~N}^{\circ}\right.$ Nulas $+0,3 * \mathrm{~N}^{\circ}$ Baixas $+0,6^{*} \mathrm{~N}^{o}$ Médias $+\mathrm{N}^{\circ}$ Altas $) /\left(\mathrm{N}^{o}\right.$ Empresas $)$

Figura 2 - Índice de Importância* Atribuído pelas Empresas às Formas de Cooperação Realizadas com os Compradores dos Principais Mercados Mundiais (EUA, EUROPA) Entre os Anos de 2001 e 2003 - Arranjo Produtivo do Mobiliário da Região Norte, SC - 2004 
A tabela 2 identifica os principais resultados das interações com os compradores externos ${ }^{14}$ na avaliação das empresas do arranjo. De forma geral, as empresas destacam significativas melhorias na qualidade dos processos em função do acesso ao mercado externo.

Esta forma de inserção possibilitou importantes incrementos e upgrading em processos, especialmente para as pequenas e médias empresas. Entretanto, para as grandes empresas, estes efeitos foram mais reduzidos, principalmente em decorrência destas já possuírem elevado nível nas suas capacitações tecnológicas. Estas melhorias também se refletiram no produto e ampliaram as oportunidades de negócio e a inserção no mercado externo.

As entrevistas realizadas com os agentes exportadores e as instituições de apoio confirmam as vantagens apontadas pelas empresas. Segundo a Abimóvel, as melhorias das condições de comercialização estão diretamente associadas aos melhoramentos nos processos produtivos e esses refletindo em melhoramentos na qualidade dos produtos.

Tabela 2 - Índice de Importância* dos principais resultados das interações realizadas com os compradores dos principais mercados mundiais (EUA, EUROPA) - Arranjo Produtivo do Mobiliário da Região Norte de Santa Catarina - 2004

\begin{tabular}{|c|c|c|c|}
\hline Descrição & Pequena & Média & Grande \\
\hline Melhoria na qualidade dos produtos & 0,60 & 1,00 & 0,60 \\
\hline Desenvolvimento de novos produtos & 0,65 & 0,60 & 0,80 \\
\hline Melhoria nos processos produtivos & 1,00 & 0,80 & 0,60 \\
\hline Melhorias nas condições de fornecimento dos produtos & 0,80 & 0,80 & 0,80 \\
\hline Melhor capacitação de recursos humanos & 0,45 & 0,30 & 0,30 \\
\hline Melhoria nas condições de comercialização & 0,60 & 0,60 & 0,60 \\
\hline Introdução de inovações organizacionais & 0,80 & 1,00 & 0,45 \\
\hline Novas oportunidades de negócios & 1,00 & 0,80 & 1,00 \\
\hline Maior inserção da empresa no mercado externo & 1,00 & 1,00 & 0,80 \\
\hline
\end{tabular}

Fonte: Pesquisa de Campo

*Índice $=\left(0^{*} \mathrm{~N}^{\mathrm{o}}\right.$ Nulas $+0,3 * \mathrm{~N}^{\circ}$ Baixas $+0,6^{*} \mathrm{~N}^{o}$ Médias $+\mathrm{N}^{\mathrm{o}}$ Altas $) /\left(\mathrm{N}^{\mathrm{o}}\right.$ Empresas $)$

\footnotetext{
${ }^{14}$ Faz-se necessário ressaltar que a forma de inserção das pequenas empresas é diferente das médias e grandes empresas. Geralmente estas participam do comércio exterior como subcontratada de outras empresas em alguma etapa do processo produtivo.
} 
Inserção em cadeias globais de valor: influência da governança externa sobre a indústria do mobiliário do Estado de Santa Catarina

A figura 3 mostra o índice de importância do tipo de informação transferida às empresas pelos compradores, que são as características e tendências do design. Os compradores internacionais, especialmente os "compradores especializados", desenvolvem pesquisas nos mercados consumidores e identificam as principais tendências de design, passando para as empresas as especificações técnicas e algumas vezes até mesmo os protótipos do móvel a ser produzido, criando a possibilidade de imitação. Também é considerada importante a absorção de informações pelas empresas sobre as características de mercado repassadas pelos compradores externos.

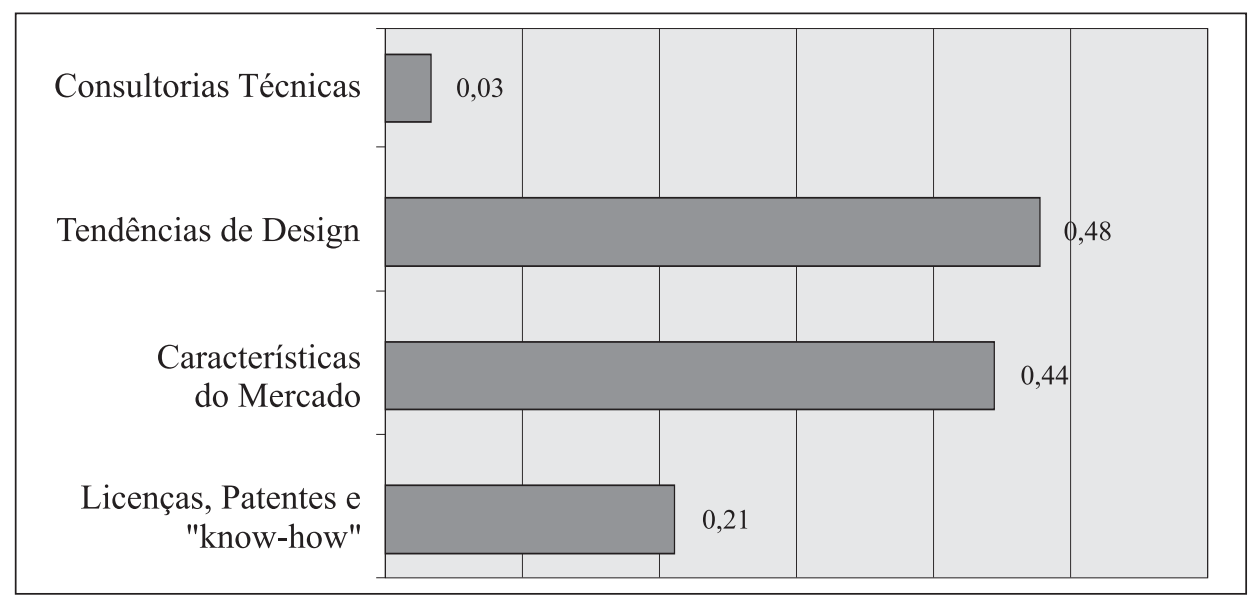

Fonte: Pesquisa de Campo

$*$ Índice $=\left(0 * \mathrm{~N}^{\mathrm{o}}\right.$ Nulas $+0,3 * \mathrm{~N}^{\mathrm{o}}$ Baixas $+0,6^{*} \mathrm{~N}^{\mathrm{o}}$ Médias $+\mathrm{N}^{\mathrm{o}}$ Altas $) /\left(\mathrm{N}^{\mathrm{o}}\right.$ Empresas $)$

Figura 3 - Índice de Importância* das Informações Transferidas pelos Compradores Externos, EUA e EUROPA - Arranjo Produtivo da Região Norte de Santa Catarina - 2004

Outro ponto avaliado foi a transferência de licenças e patentes, ou know-how. Contudo, estas formas de troca de informações ocorrem de maneira isolada em raras ocasiões. Em alguns casos onde há relações de confiança entre os compradores externos, especialmente "redes de lojas varejistas", ou agentes e as empresas, esta é uma prática comum. Transferências de informações através de consultorias especializadas são praticamente inexistentes e, quando ocorrem, são no sentido de inspeção das condições produtivas das empresas. 
As principais dificuldades para o acesso ao mercado exportador, com maior referência aos da EUROPA e EUA, estão relacionadas na figura 4. De acordo com as empresas, o preço é o fator determinante para a inserção no mercado externo, principalmente se o acesso for através de "compradores especializados", pois estes possuem fornecedores em diversos países e consideram o preço como fator determinante para a escolha dos fornecedores.

Outro fator evidenciado que dificulta a inserção no mercado externo é a dificuldade encontrada no transporte portuário. A falta de investimentos nos portos brasileiros gera problemas estruturais aumentando o tempo de carga, de descarga e de armazenagem, o que aumenta os custos para as companhias de navegação que acabam por reduzir as linhas na América do Sul em busca de opções mais lucrativas. Outro ponto ressaltado pelas empresas que agrava este problema é o sucateamento da "Marinha Mercante" brasileira.

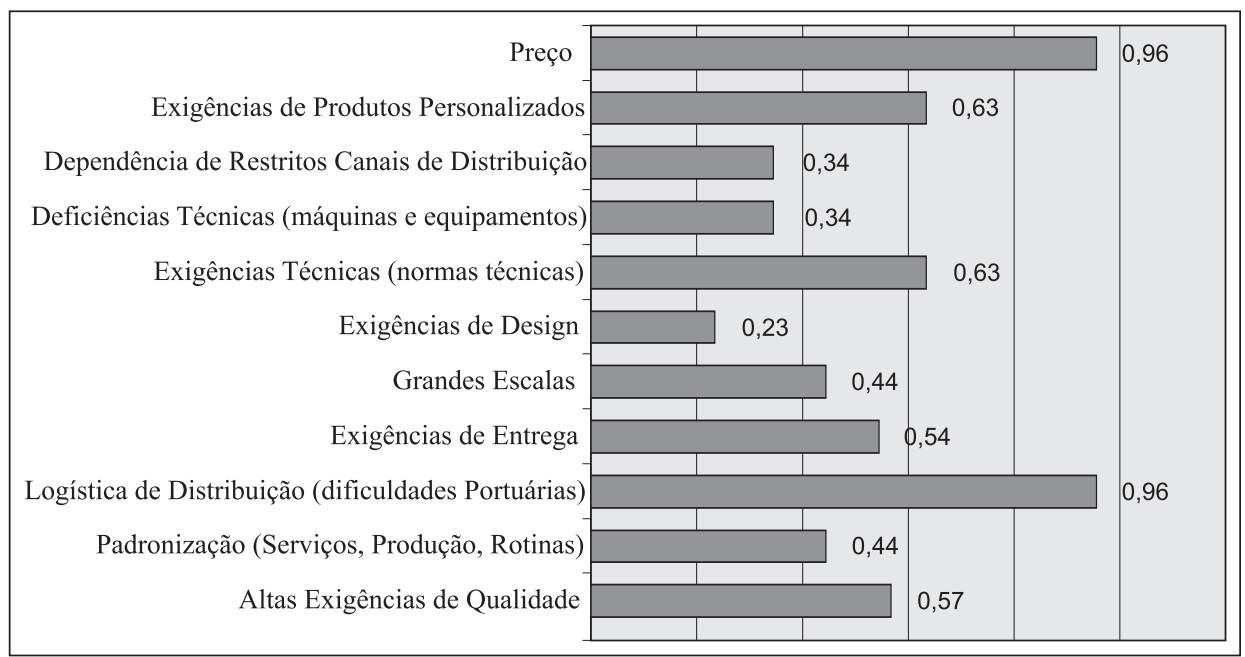

Fonte: Pesquisa de Campo

$*$ Índice $=\left(0^{*} \mathrm{~N}^{\mathrm{o}}\right.$ Nulas $+0,3 * \mathrm{~N}^{\mathrm{o}}$ Baixas $+0,6^{*} \mathrm{~N}^{\mathrm{o}}$ Médias $+\mathrm{N}^{\mathrm{o}}$ Altas $) /\left(\mathrm{N}^{\mathrm{o}}\right.$ Empresas $)$

Figura 4 - Índice de Importância* das Principais Dificuldades ao acesso principal mercado de exportação (EUROPA e EUA) - Arranjo Produtivo do Mobiliário da Região Norte de Santa Catarina - 2004

A customização de produtos é um fator que dificulta a inserção externa das empresas devido ao alto grau de flexibilidade exigido nos processos produtivos. 
Inserção em cadeias globais de valor: influência da governança externa sobre a indústria do mobiliário do Estado de Santa Catarina

Da mesma forma, a exigência de normas técnicas é considerada como uma dificuldade em decorrência das especificidades de cada mercado consumidor.

\section{INSERÇÃO EXTERNA E POSSIBILIDADES DE APRENDIZA- GEM NOS ARRANJOS PRODUTIVOS LOCAIS}

Este trabalho procurou analisar as possibilidades de aprendizagem nas empresas localizadas em arranjos produtivos do mobiliário proporcionadas pelas relações com os compradores externos que participam das cadeias globais de valor. A localização das empresas em arranjos produtivos permite a essas empresas explorarem externalidades locais que alavancam suas vantagens competitivas. Uma maior divisão do trabalho no local, criando complementaridades produtivas, proporciona o desenvolvimento de especializações locais. Tais especializações ampliam as possibilidades de flexibilização dos processos produtivos que possibilitam condições para inserção nos mercados internacionais. No entanto, os efeitos desta inserção sobre a criação de competências nas empresas dependem do tipo de comprador externo.

No arranjo localizado na região Oeste do Estado, a menor divisão do trabalho se traduz também em menor inserção nos mercados internacionais, enquanto que o arranjo localizado da região Norte do Estado, com uma intensa divisão do trabalho e maior complementaridade, exporta parte significativa da sua produção.

As características do padrão de aprendizagem em indústrias tradicionais, como a capacidade para absorver inovações geradas nos setores produtores de equipamentos e insumos, e a necessidade de realizar constantemente melhoramentos no design, fazem com que, além de fortes interações locais, as relações com agentes externos aos arranjos sejam uma importante fonte de informação.

A observação das relações entre as empresas e os compradores externos nos dois arranjos localizados em Santa Catarina evidenciou estes aspectos. No arranjo da região Norte do Estado ocorreu o desenvolvimento de um segmento de agentes exportadores que passaram a atender também as empresas do arranjo do mobiliário em formação no Oeste. Além disto, criaram-se também redes de subcontratação que possibilitam às pequenas empresas participarem como fornecedoras das médias e grandes exportadoras. Este aspecto é mais evidente no arranjo da região Norte e bastante incipiente no da região Oeste de Santa Catarina. 
De acordo com as entrevistas realizadas, conclui-se que as relações entre os compradores externos e as empresas locais proporcionam a realização de upgrading em processo. Contudo, as possibilidades de upgrading funcional e em produto dependem das capacitações locais desenvolvidas pelas empresas. Mas as possibilidades para ampliar a capacitação tecnológica não decorrem diretamente de processos interativos de aprendizagem com os agentes externos. As formas de interações com tais agentes, quer pelas características do padrão de concorrência, que exige domínio sobre os processos de design, quer pela intensidade do fator preço no processo competitivo, não estimula de maneira significativa formas de relações de natureza cooperativa. No entanto, o esforço das empresas para manterem-se neste mercado bastante competitivo estimula a aprendizagem que acaba por ampliar as capacitações, principalmente em processo. Este aspecto, aliado à sinergia que decorre das relações entre os agentes internos ao arranjo, redes de subcontratação, possibilita manter as condições de competitividade.

As observações empíricas sobre as relações dos diferentes compradores do mercado internacional, conforme apontado na literatura, têm impactos diferenciados sobre as capacitações das empresas locais. No caso dos arranjos estudados, estas relações ocorrem, ou através dos agentes de exportação, ou diretamente, principalmente com os "compradores especializados". Estas relações, apesar de proporcionarem diversos efeitos positivos reconhecidos pelos agentes entrevistados e criar condições para manter ou até ampliar sua posição nos mercados internacionais, não proporcionam subsídios para realização de upgrading funcional, ou seja, para mover-se para segmentos com maior agregação de valor nas cadeias produtivas.

\section{INCLUSION IN GLOBAL VALUE CHAINS: INFLUENCE OF FOREIGN GOVERNANCE ON THE FURNITURE INDUSTRY OF THE SANTA CATARINA STATE}

\footnotetext{
Abstract

This study examines the relationships of companies in the furniture sector of Santa Catarina state that are embedded in local production arrangements with international buyers. The specific focus of analysis is the identification
} 
Inserção em cadeias globais de valor: influência da governança externa sobre a indústria do mobiliário do Estado de Santa Catarina

of opportunities for technological upgrading through interactive learning with international buyers. The furniture industry of Santa Catarina state is responsible for $50 \%$ of national exports of furniture and, in the main consumer markets, U.S. and Europe, the marketing activity is done by large international distributors. The aim is to investigate the possibility of enterprises in productive clusters to obtain sustainable competitive advantage in international markets, partly linked to its relations within global chains. We evaluate, specifically, the learning processes associated with technological relations that furniture companies in Santa Catarina state hold with the global chains. Based on the neo-Schumpeter's approach, which addresses the processes of learning technology, a field research was conducted using a structured questionnaire for the analysis of the characteristics of technological capabilities of selected companies, located in production clusters of Santa Catarina.

Keywords: furniture industry; learning technology; global chains.

\section{REFERÊNCIAS BIBLIOGRÁFICAS}

ALICE WEB. Ministério do Desenvolvimento, Indústria e Comércio Exterior-MDIC. Sistema de Análise das Informações de Comércio Exterior via Internet - Alice Web. Site: http://www.mdic.gov.br, 2004.

BRESCHI, S.; MALERBA, F.; Sectoral Innovation Systems: Technological Regimes, Schumpeterian Dynamics, and Spatial Boundaries. In EDQUISI, C.; (ed), Systems of Innovation; technologies, institutions and organizations. London: Pinter, 1997.

CAMPOS, R. R.; CÁRIO, S. A. F.; NICOLAU, J. A.; VARGAS, G. T.(2003) Aprendizagem por interação: pequenas empresas em sistemas produtivos e inovativos locais. In: (Orgs.) LASTRES, H. M. M.; CASSIOLATO, J. E.; MACIEL, M. L. Pequena Empresa: Cooperação e Desenvolvimento Local. Rio de Janeiro: Relume Dumará: UFRJ, Instituto de Economia. 
CASSIOLATO, J. E., LASTRES H. M. M.(2003) O foco em arranjos produtivos locais e inovativos de micro e pequenas empresas. In: (Orgs.) LASTRES, H. M. M.; CASSIOLATO, J. E.; MACIEL, M. L. Pequena Empresa: Cooperação e Desenvolvimento Local. Rio de Janeiro: Relume Dumará: UFRJ, Instituto de Economia.

HUMPHREY, J. and SCHMITZ, H. (2001) Governance and Upgrading: linking industrial cluster and global value chain research. IDS Working Paper, Brighton: Institute of Development Studies.

KAPLINSKY, R.; MEMEDOVIC, O.; MORRIS, M.; READMAN. J.; The Global Wood Furniture Value Chain: What Prospects for Upgrading by Development Countries - The Case of South Africa. Sectoral Studies Series. UNIDO. Viena. 2003.

LUNDVALL, Bengt-Åke (edited by). National Systems of Innovation: towards and theory of innovation and interactive learning. London: Printer Publishers, 1992.

MALERBA, F. Learning by Firms and Incremental Technical Change. The Economic Journal. July, 845-859, 1992.

MINISTÉRIO DO TRABALHO E EMPREGO. Departamento de Emprego e Salários. Bases estatísticas. Brasília, 2001. RAIS - Relação Anual de informações sociais.

RABELLOTTI, R.; PIETROBELLI, C.; GIULIANI, E.; Upgrading in Global Value Chains: Lessons from Latin American Clusters. Clusters, Industrial Districts and Firms: The Challenge of Globalization. Modena. Italy, 12-13 September, 2003.

SCHMITZ, H. KNORRINGA, P. (1999) Learning From Global Buyers. IDS Working Paper, Sussex: Institute of Development Studies. 